\title{
Multiband Slotted Planar Inverted-F Antenna using Reactive Impedence Surface for Wireless Applicatios
}

Tejaswi Mahaling J Jadhav ( $\boldsymbol{\nabla}$ tejaswi.jadhav@walchandsangli.ac.in )

Walchand College of Engineering https://orcid.org/0000-0003-2614-4873

\section{Research Article}

Keywords: Planar inverted-F antenna, Reactive impedance surface, Gain, Multiband, Slots

Posted Date: August 30th, 2021

DOl: https://doi.org/10.21203/rs.3.rs-853528/v1

License: (1) (1) This work is licensed under a Creative Commons Attribution 4.0 International License.

Read Full License 


\title{
Multiband Slotted Planar Inverted-F Antenna using Reactive Impedence Surface for Wireless Applicatios
}

\begin{abstract}
This research work presents a low profile slotted planar inverted$\mathrm{F}$ antenna (PIFA) on a reactive impedance surface (RIS) for multiband. The quad-band frequency antenna for $2.4 \mathrm{GHz}$ (WLAN), $4.2 \mathrm{GHz}$ (C-band satellite downlink), 7.1 GHz (C-band satellite uplink), and $9 \mathrm{GHz}$ (X-band )for wireless applications. The structure of the proposed PIFA has a compacted patch size of $23.33 \mathrm{~mm} \times 2.66 \mathrm{~mm} \times 1 \mathrm{~mm}$ placed on a dielectric substrate flame retardant 4 (FR4) material, along with tangent loss $=0.02$. The proposed antenna used two dielectric substrates whose heights are $h_{1}=1.59 \mathrm{~mm}$ and $h_{2}=1 \mathrm{~mm}$. The rectangular slot is added in a radiating patch of the PIFA for multiband operations. The proposed antenna improves the parameters such as reduction scale, efficiency, narrow bandwidth, and gain enhancement. The slotted PIFA shows a quad-band with an $S_{11}<-10 \mathrm{~dB}$ bandwidth of approximately $15.83 \%$ $(2.24-2.62 \mathrm{GHz}), 11.19 \%(3.93-4.4 \mathrm{GHz}), 12.67 \%(6.90-7.80 \mathrm{GHz})$ and $10.55 \%$ $(8.29-9.24 \mathrm{GHz})$ under measurement. The proposed antenna design is excited by $50 \Omega$ microstrip line feed. The antenna exhibits radiation pattern, gain, and impedance matching across their operating bandwidths to demonstrate the benefits of multiple PIFA.
\end{abstract}

Keywords Planar inverted-F antenna - Reactive impedance surface - Gain · Multiband · Slots

\section{Introduction}

Recently, in our everyday life, the growth of wireless devices, the demand for smartphones to change, miniature, low-cost, better mobility, and lightweight antenna. The handheld wireless device always suffers narrow impedance, less bandwidth, multiband, and less gain. The PIFA structure is a simple, low 
profile, and flat that allows an omnidirectional pattern, a stable, and rational benefit in manufacturing, in discussed [1. Due to its tactlessness property of the antenna, the PIFA gives more resistance elasticity for multiband mobile devices 2. PIFA is usually suitable to use of multiband for industrial scientific and medical (ISM), long-term evolution (LTE), the global framework for handheld phones, Wi-max, WLAN, and other wireless technologies are discussed in [3. The L-loaded PIFA has added the open end of capacitive load for additional antenna miniaturization. The electrically unconnected compact, novel, and multiband PIFA using multi-strip ground 4. The combination of the thickness and feed position of antenna substantially providing at low frequency, increase the bandwidth, change and enhance at the desired frequencies, the gain, and the radiation effectiveness for the resonant frequency bands and the small ultra-thin PIFA with independent power [5. A planar microstripfed triple-band PIFA is reported for the GSM835, DCS1940, and Wi-Fi 2340 bands 6 . The new design multiband PIFA has simulated cellular phones at different frequency bands is explained in 7]. Tri-band PIFA for ISM, GSM and DCS applications 8 and fractal PIFA with three separate iterations for mobile phones [9]. For wireless communication systems, a triple-band PIFA with a parasitic element and the compact triple-band internal mobile antenna for IEEE 802.11[10. The four slots joined into a radiating patch, and the ground surface of PIFA with a maximum gain 11 and slot dimension had carried out to obtain a robust antenna design using the Taguchi quality method against changes in uncontrollable factors [12. The antenna efficiency predicted by electromagnetic software to validate the design and compared to fabricated results 13, [14. Rectangular complementary split-ring resonator (CSRR) for PIFA using branch-line has explained in [15]. The PIFA antenna was designed and developed by adding two parasitic elements with rectangular slots placed under the radiating patch to obtain a triple-band operation. In [16] the three resonant modes using an F-T shaped radiating structure by a trapezoidal feeding plate has produced and enhancing the antenna's impedance bandwidth. The microstrip antenna composed of a fork-shaped strip etched on the rectangular patch [17 and a rectangular-defected ground plane 18, 19. On the bottom side, a partial ground plane that acts as a defective ground structure is added, and it is built to provide appropriate bandwidths for multi-frequency bands [20, 21].

The wireless handheld device system is compact, needs size reduction, and multiband. Miniaturization and bandwidth enhancement of the antenna becoming deliberations for wireless handheld devices [22, 23]. The low profile PIFA is an internal mobile antenna and easy to implement, which are applicable in several areas like space, military, wireless and commercial applications 24. Therefore, the PIFA is an internal mobile antenna that compensates problems associated with polarisation, narrow bandwidth, lesser gain, and a smaller power handling capability. The metamaterial periodic structure of the RIS has demonstrated the ability to decrease the size of antennas and the cutting slot used for multiband operation. In this research, reduce the disadvantages of PIFA with an optimal technique and introduced a new, innovative, low profile 
effective design of a slotted PIFA with RIS is designed, simulated, analyzed, and developed for multiband operations.

\section{ANTENNA DESIGN}

The conceptual framework of the slotted PIFA with RIS has shown in Fig. 1. The workflow of the proposed antenna simulated, analyzed, optimized, fabricated, and compare results. The conventional PIFA has a radiating patch, a ground plane, a shorting pin, a dielectric substrate (FR4), and a microstrip feed presented in [25. RIS is a periodic metamaterial above the ground plane of slotted PIFA, as shown in Fig. 2(a). A simple structure of the PIFA is known as a "Conventional antenna". The geometric parameters of the radiating patch have $23.33 \times 2.66 \times 1 \mathrm{~mm}$, and the ground plane is $56.4 \mathrm{~mm} \times 41.68 \mathrm{~mm}$.It's made up of a monopole antenna that's grounded at one end and runs parallel to the ground plane. The antenna is fed from a distance from the grounded end, at an intermediate position. Because of its space-saving features, it is most commonly used in mobile wireless devices as a PIFA. An antenna slot has made up of metal. The rectangular slots to cut a flat plate or holes on the surface of the radiating patch. If the metallic plate of the PIFA drives an operating frequency, then radiates electromagnetic waves in the antenna. Fig. 2(b) shows a modified PIFA with a rectangular slot of an antenna. Fig. 3(a) illustrates the optimized geometrical dimensions of the slotted PIFA, which is designed by the transmission line model. Fig. 3(b) shows the periodic structure of metallic square unit cells. The RIS consists of periodic structures $5 \times$ 6 array of square unit cells. The adjacent dimension is set to have $g_{1}=0.342$ $\mathrm{mm}, g_{2}=0.28 \mathrm{~mm}, a_{1}=0.8 \mathrm{~mm}$ and $a_{2}=0.9 \mathrm{~mm}$ for the periodic metal unit cells. RIS has been using for size reduction, impedance matching, and improvement of impedance bandwidth. The overall dimensions, as shown in table 1, of the adjusted slotted PIFA with RIS. Fig. 4 shows the front view (cross-section) of the modified slotted PIFA with RIS. There are two h1 and h2 dielectric substrates in the improved proposed antenna, which height is $h_{2}$ $=1 \mathrm{~mm}$ and $h_{1}=1.59 \mathrm{~mm}$. The surface of the RIS is among $h_{1}$ and $h_{2}$ dielectric substrates. The feed from the slotted PIFA and the antenna ground plane directly joined using the surface mount sub-miniature (SMA) connector. The SMA feeding probe connector does not explicitly contact the RIS structure, so the feed point mount on one corner of the radiating patch. The slotted PIFA has a frequency band of $2.4 \mathrm{GHz}$ and impedance bandwidth of $-10 \mathrm{~dB}$, ranging from 2.16 to $2.56 \mathrm{GHz}$. Alternatively, the antenna limit to a single choice band and low matching impedance has shown in Fig. 5(a).

The slotted method improves the performance parameter of the antenna. The slot of the antenna is useful for compact size, easy to integrate for mobile devices. It also provides a wideband and a good option for design a multiband antenna. Therefore, a rectangular slot with PIFA is introduced in the "proposed antenna" to enrich its operational capabilities. The antenna slots change the surface current distribution as a consequence, enabling the pro- 


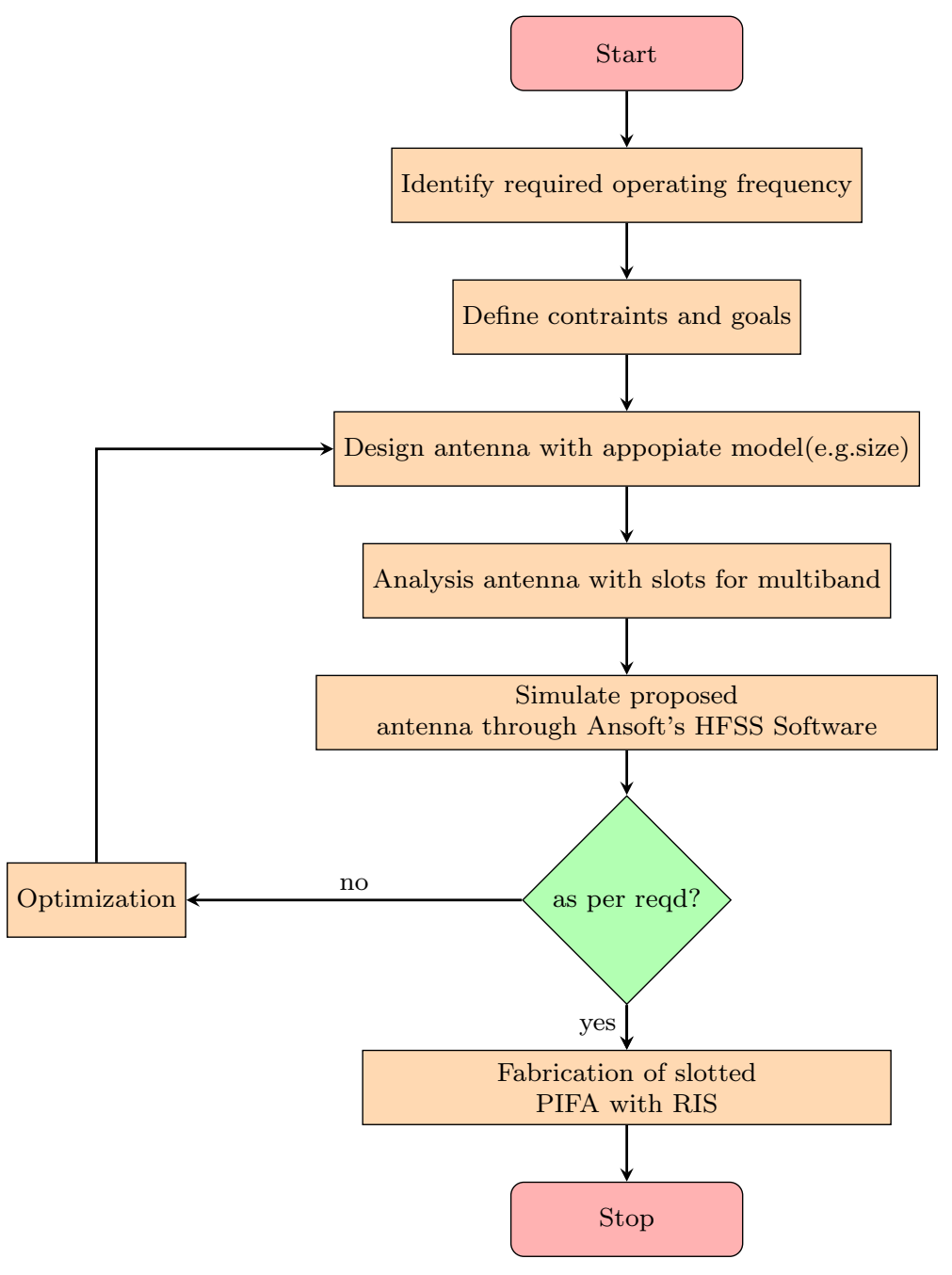

Fig. 1: Overall performance of slotted PIFA with RIS

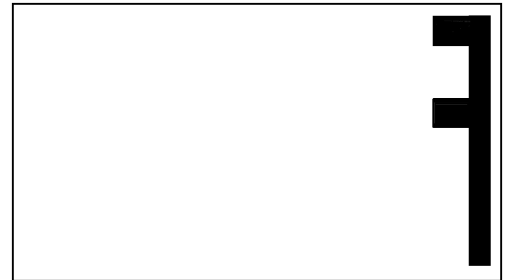

(a) Conventional PIFA

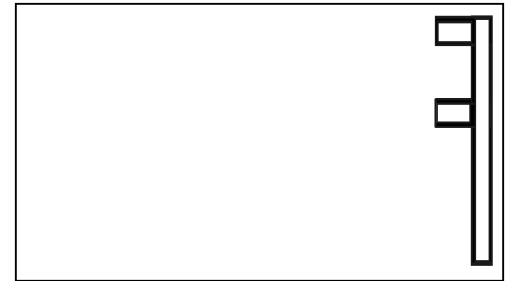

(b) Proposed Slotted PIFA

Fig. 2: Evalution stage of PIFA 


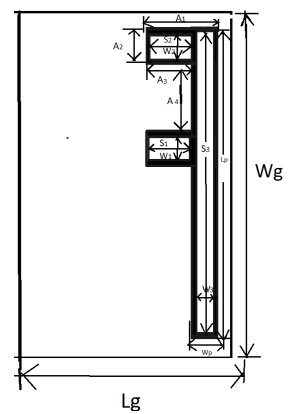

(a) Geometrical view of slotted PIFA

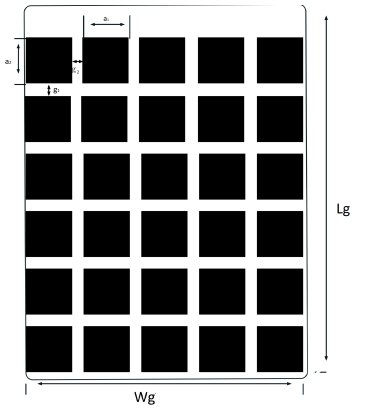

(b) Top view periodic arragement of the $5 \times 6$ RIS array

Fig. 3: Structure of proposed antenna

posed design to operate at frequency bands of 2.4,4.2, 7.1, and $9 \mathrm{GHz}$ and rise the total current length direction. The simulated impedance bandwidth has shown in Fig. 5(a), and the voltage standing wave ratio (VSWR) have illustrated in Fig. 5(b) of the proposed antenna. It noted that the VSWR value is almost 1.60 at $2.4 \mathrm{GHz}$ frequency, which is precisely competent in the manufacturing phase. VSWR varies between 1 and 2 , then the antenna gives better performance and acts as a better radiator. The rectangular slot $\left(S_{1} \times\right.$ $\left.W_{1}\right)$ is affected on the radiating patch to change the resonance at $2.4 \mathrm{GHz}$. The $\left(S_{2} \times W_{2}\right)$ and $\left(S_{3} \times W_{3}\right)$ able to change the frequency band and also to improve the impedance matching. The $\left(S_{2} \times W_{2}\right)$ slot changes the 4.2 and 7.1 $\mathrm{GHz}$ resonance frequency of the proposed antenna. The rectangular antenna slot $\left(S_{3} \times W_{3}\right)$ is included in the slotted PIFA design to generate a resonance frequency at $9 \mathrm{GHz}$. The antenna slot $\left(S_{1} \times W_{1}\right)$ provides impedance balancing of multiband operating frequencies using the $\lambda / 4$. The proposed antenna provides impedances $50 \Omega$ using the lumping port excitation mechanism fed into the radiating patch. The RIS discusses in the next subsection.

Table 1: Geometric parameters of Slotted PIFA

\begin{tabular}{cccc}
\hline Parameters & Value $(\mathrm{mm})$ & Parameters & Value $(\mathrm{mm})$ \\
\hline $\mathrm{Lg}$ & 56.4 & $\mathrm{Wg}$ & 41.68 \\
$\mathrm{Lp}$ & 23.33 & $\mathrm{Wp}$ & 2.66 \\
$A_{1}$ & 7.26 & $A_{2}$ & 2.6 \\
$A_{3}$ & 4.6 & $A_{4}$ & 5.8 \\
$S_{1}$ & 3.7 & $W_{1}$ & 1.8 \\
$S_{2}$ & 3.7 & $W_{2}$ & 1.8 \\
$S_{3}$ & 22.5 & $W_{3}$ & 1.8 \\
$h_{1}$ & 1.59 & $\epsilon \mathrm{r}$ & 4.4 \\
\hline
\end{tabular}




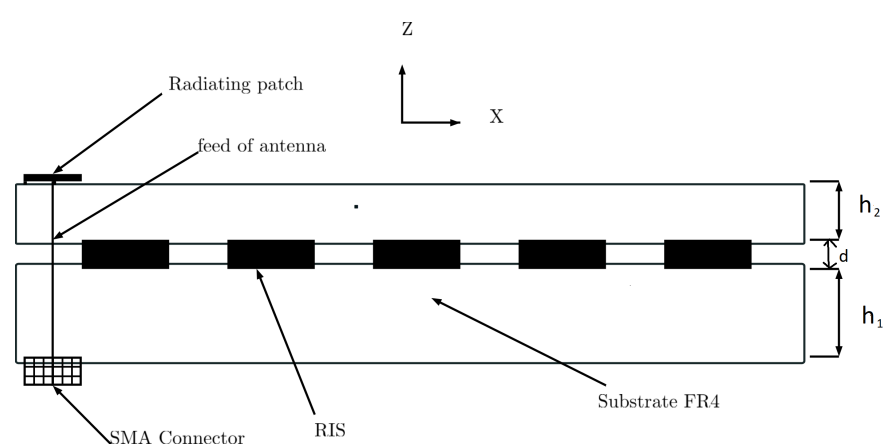

Fig. 4: Cross sectional view of slotted PIFA with RIS

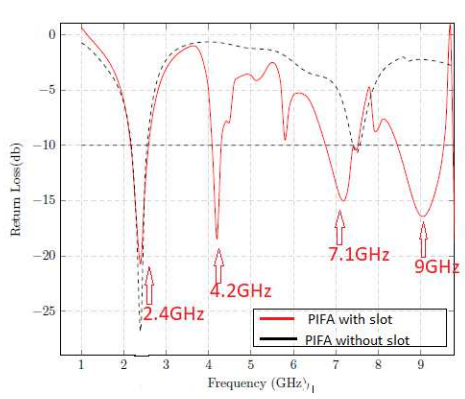

(a) Return Loss

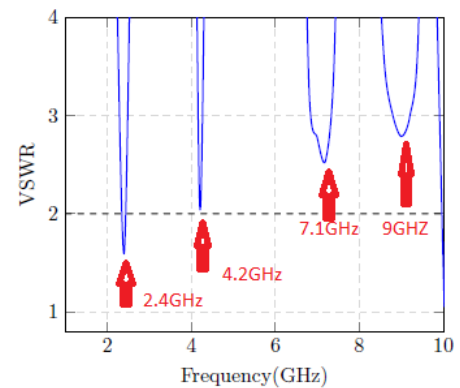

(b) VSWR

Fig. 5: Simulated return loss and VSWR of slotted PIFA

\subsection{RIS for slotted PIFA}

The RIS is a metamaterial, relaxed construction of two-dimensional arrangement, periodically metallic square unit cells, below the radiating patch, and dielectric substrate backed on the ground. RIS has enhanced miniaturization, impedance bandwidth, and multiband performance 26. Perfect magnetic conductor (PMC) and electric conductor (PEC) boundaries around the RIS and exciting with a transverse electromagnetic (TEM) mode of an antenna to obtain broad bandwidth and miniaturization. Robust electromagnetic coupling between PEC (PMC) boundaries, the radiating patch, and the ground surface is the miniaturization of the antenna hence the near-field of slotted PIFA containing electromagnetic energy expansion with the dielectric substrate.

The PIFA miniaturization improved features such as less matching impedance, low gain, and narrow bandwidth for corporate costs. The reactive impedance surface reduces the reciprocal coupling between the radiating patch and the ground plane, the output substantially recovered from the PEC and PMC surfaces, size reduction, narrow bandwidth, and back radiation are improved. The RIS is a periodic structure that operates parallel inductive and capacitive 
circuits. It also increases the bandwidth and provides better impedance characteristics over RIS with the same dielectric substrate and radiating patch. The periodic arrangement of PIFA is mounting at one end of the dielectric substrate. The ground surface moved away from the radiating element because the micro-strip ground has under its substrate. The fringing field created a small area, so the ground plane moves away from the radiating to have better radiation emission and the complete ground and partial ground around the radiating element. Here the proposed model ground and the feed are also connected by the coaxial probe feed. The connector of the feed points a little bit away from the radiating portion to avoid interaction between the feed and metasurface. It is connected by a small stripline so that its resonant frequency is not determined by conventional equation but by simulation. Instead of the ground plane insert metamaterial, to enhance its radiation with the tuning, change the dimensions and different frequencies. It initially to design, to mitigate the surface waves the way how these high impedance structures work. If the ground plane has placed below the PIFA, it generates image currents of its reflection. The radiation energy has confined to a small place so, the ground reflection can be out of phase resulting from the disturbance in the radiation pattern. The better performance of the antenna RIS shifts the additional energy incident on it. So the energy is added in a constructive interference way instead of canceling it. For better matching to the PIFA, the metasurface had designed by the analysis described. The variation in $\mathrm{L}$ and $\mathrm{C}$ metasurfaces is based on the gap between the metal sheets and the metal pin height. The PIFA work at the different resonant frequencies with enhanced BW and good radiation pattern.

\section{Analysis of slotted PIFA}

\subsection{Antenna Equation}

The design of slotted PIFA is using the Transmission line model, which essential three parameters like a resonance frequency $\left(f_{0}\right)$, selection of a dielectric substrate $\left(\epsilon_{r}\right)$, and substrate height $(\mathrm{h})$. The geometric radiating patch length $\left(L_{P}\right)$, patch width $\left(W_{P}\right)$, and different slots in the patch had calculated by using the mathematical model [27. Calculated dimensions have been optimizing with their respective frequency bands. The impedance bandwidth is directly proportional to the thickness of the substrate and inversely proportional to the square root of the dielectric constant of the substrate $\left(\epsilon_{r}\right)$. The width of the patch is calculated by using equ(1)as follows:

$$
\begin{gathered}
W p=\frac{c}{2 f_{0} \sqrt{\frac{\epsilon_{r} e f f+1}{2}}} \\
\frac{\Delta L}{h}=0.412 \frac{\subset \epsilon_{e f f}+0.3 \supset \sqsubset \frac{w}{h}+0.264 \sqsupset}{\subset \epsilon_{e f f}-0.258 \supset \sqsubset \frac{w}{h}+0.8 \sqsupset}
\end{gathered}
$$



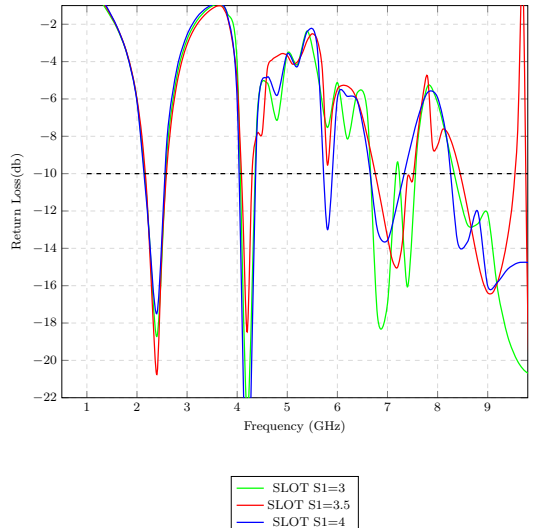

(a)
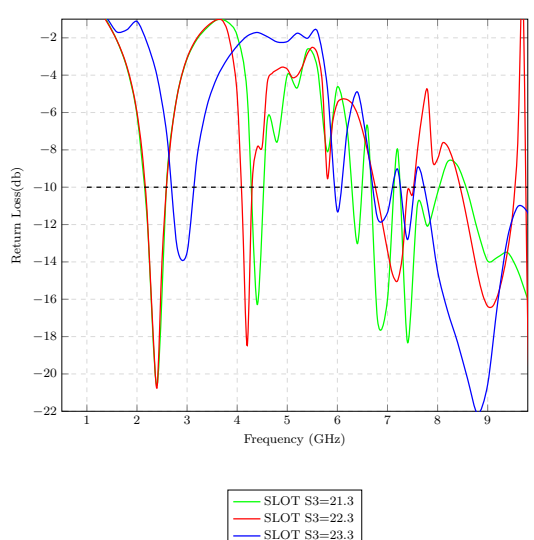

(c)

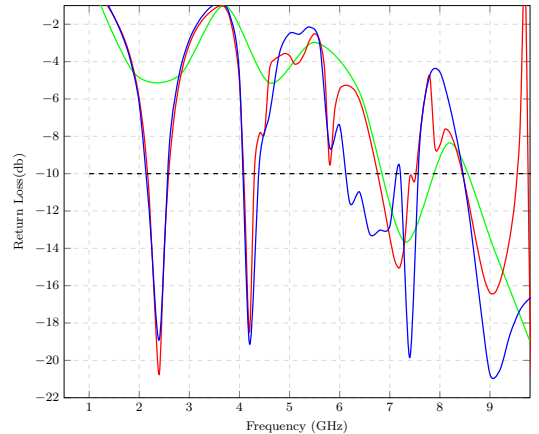

$\begin{array}{r}\text { - SLOT } S_{2}=3 \\ \text { - SLOT } 22=3.5 \\ \hline\end{array}$

(b)
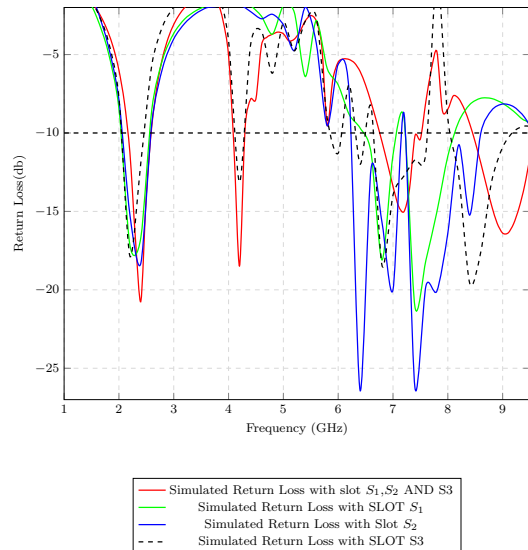

(d)

Fig. 6: (a)Variation in slot $S_{1}$ (b)Variation in slot $S_{2}$ (c) Variation in slot $S_{3}$ (d)Return Loss with slot $S_{1}$, slot $S_{2}$ and slot $S_{3}$ of slotted PIFA

For a resonance frequency $f_{0}$, the effective length by using equ(3)is

$$
L_{e f f}=\frac{c}{2 f_{0} \sqrt{\epsilon_{\text {reff }}}}
$$

The length of the patch using equ(4) is

$$
L_{p}=\lambda g / 4
$$

Resonance frequency of PIFA antenna for $T M_{m n}$ mode is given as: Where $\mathrm{m}$ and $\mathrm{n}$ modes are alongside $\mathrm{L}$ and $\mathrm{W}$ respectively.

Where, $\mathrm{A}$ is a fixed and,h is the substrate height $=1.6 \mathrm{~mm}$, dielectric constant 


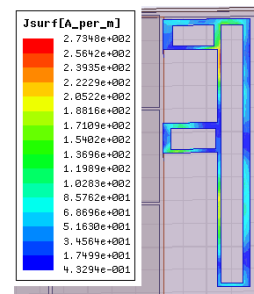

(a)

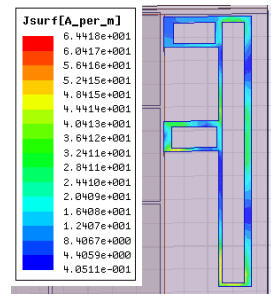

(b)

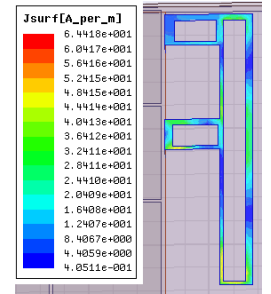

(c)

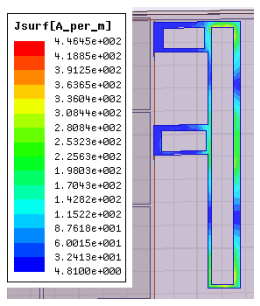

(d)

Fig. 7: Surface current distribution of slotted PIFA at (a) 2.4, (b) 4.2, (c) 7.1 and (d) $9 \mathrm{GHz}$

$=4.4$, The effective dielectric constant is measured by using equ(5)and (6)as the width of the strip line $\left(W_{3}\right)$ and the length of the strip $\left(S_{3}\right)$

$$
\frac{W_{3}}{h}=\frac{8 \exp (A)}{\exp (2 A)-2}
$$

and

$$
A=\frac{Z L}{60}\left(\frac{\varepsilon_{r}+1}{2}\right)^{\frac{1}{2}}+\left(\frac{\epsilon_{r}-1}{\epsilon_{r}+1}\right)\left(0.23+\frac{0.11}{\epsilon_{r}}\right)
$$

\subsection{Parametric Study}

The parametric study of the slotted PIFA with RIS had performed, and its simulation results have illustrated in Fig. 6 . The analysis is achieved by varying antenna rectangular slots such as $S_{1}, S_{2}$, and $S_{3}$ while maintaining constant other measurements. Fig. 6(a) shows the variance of slot $S_{1}$ from $3 \mathrm{~mm}$ to $4 \mathrm{~mm}$ at phase $0.5 \mathrm{~mm}$ is observed, thus influencing the operating frequency of $2.4 \mathrm{GHz}$. Fig. 6 (b) indicates the variance of slot $S_{2}$, demonstrating that the resonance frequency of $4.2 \mathrm{GHz}$ is not disrupting but the change in the operating frequency observed at 7.1 and $9 \mathrm{GHz}$, respectively. Fig. 6(c) illustrates a change in impedance bandwidth and operating bands of the antenna. When the patch length varies from $23 \mathrm{~mm}$ to $24 \mathrm{~mm}$ at phase $0.5 \mathrm{~mm}$, for $L_{P}=23.33 \mathrm{~mm}$, then improved impedance bandwidth. The frequency bands 
at $2.4,4.2,7.1$, and $9 \mathrm{GHz}$ have moved either right and left of the resonance with the variance of radiation patch slots $S_{3}$ illustrated in Fig. 6(c). Antenna deviation slots $S_{1}, S_{2}$, and $S_{3}$ are shown in Fig. $6(\mathrm{~d})$ that resonance at $7.1 \mathrm{GHz}$ is not disruptive, but the shifting of the operating frequency band observed in $2.4,4.2$, and $9 \mathrm{GHz}$, respectively. Fig. 7 shows the current distribution of the slotted PIFA. The current density is equivalent to the rectangular slot $S_{3}$ $\times W_{3}$ as illustrated in Fig. 7(a) and (b), which are resonant at 2.4, and 4.2 $\mathrm{GHz}$, respectively. The front radiating patch current had used to change the resonant frequency at 2.4 and $4.2 \mathrm{GHz}$. A larger current density had observed near the rectangular slot that is accountable at $7.1 \mathrm{GHz}$, as shown in Fig. 7(c). The resonance at $9 \mathrm{GHz}$ is indicated by the additional current path nearby $S_{1}$ and $S_{2}$ slots, as shown in Fig. $7(\mathrm{~d})$.

Table 2: Comaprison of simulated and measured results of slotted PIFA

\begin{tabular}{cccc}
\hline \multicolumn{3}{c}{ Simulated Results } \\
\hline $\begin{array}{c}\text { Frq } \\
(\mathrm{GHz})\end{array}$ & $\begin{array}{c}\text { Return } \\
\text { loss } \\
(\mathrm{dB})\end{array}$ & $\begin{array}{c}-10 \mathrm{~dB} \\
\text { impedance } \\
\text { bandwidth } \\
(\mathrm{GHz})\end{array}$ & $\begin{array}{l}\text { Band } \\
\text { width }\end{array}$ \\
\hline 2.4 & -20.7 & $2.161-2.589$ & 17.83 \\
4.2 & -18.47 & $4.082-4.300$ & 5.19 \\
7.1 & -14.9 & $6.755-7.522$ & 10.89 \\
9 & -16.38 & $8.448-9.538$ & 12.10 \\
\hline \multicolumn{3}{c}{ Measured Results } \\
\hline Frq & Return & -10 dB \\
$(\mathrm{GHz})$ & loss & impedance & Band \\
& $(\mathrm{dB})$ & Bandwidth & width \\
& \multicolumn{3}{c}{ GHz $)$} \\
\hline 2.4 & -17.12 & $2.24-2.62$ & 15.83 \\
4.2 & -15.97 & $3.93-4.4$ & 11.19 \\
7.1 & -14.73 & $6.90-7.80$ & 12.67 \\
9 & -13.70 & $8.29-9.24$ & 10.55 \\
\hline
\end{tabular}

\section{Results and discussion}

The simulated and measured performance parameters of slotted PIFA with RIS such as VSWR, return loss, gain, and radiation pattern discussed in this section.

\subsection{Return Loss}

As shown in Fig. 5(a), the reflection coefficient $\left(S_{11}\right)$ is obtained using the simulation tool. Slotted PIFA showing a quad-band with an $S_{11}<-10 \mathrm{~dB}$ 


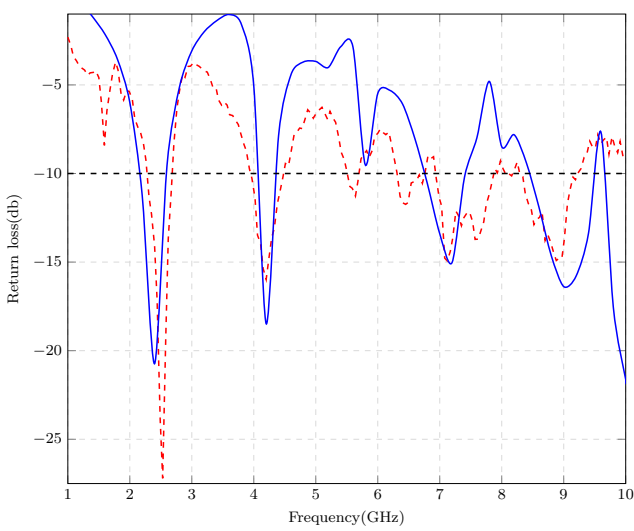

- - Measured Return Loss

(a)

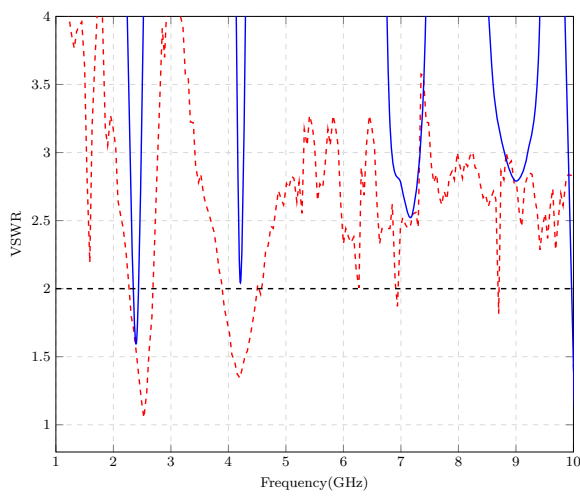

\section{-- Measured VSWR
- Simulated VSWR}

(b)

Fig. 8: (a)Measured and simulated Return Loss of slotted PIFA (b)Measured and simulated VSWR of slotted PIFA

bandwidth of approximately $17.83 \%, 5.19 \%, 10.89 \%$ and $12.10 \%$ under simulation and approximately $15.83 \%(2.24-2.62 \mathrm{GHz}), 11.19 \%(3.93-4.4 \mathrm{GHz})$, $12.67 \%(6.90-7.80 \mathrm{GHz})$ and $10.55 \%(8.29-9.24 \mathrm{GHz})$ under measurement respectively. The proposed slotted PIFA is manufactured, tested, and concluded that the RIS surface increases the broad bandwidth and gain. In the vector network analyzer (VNA), the VSWR and return loss of slotted PIFA with RIS has calculated. Table 2 shows the simulated and measured results of slotted PIFA with RIS. Fig. 8(a) displays the simulated and fabricated results obtained from output parameters such as return loss. The comparison between 


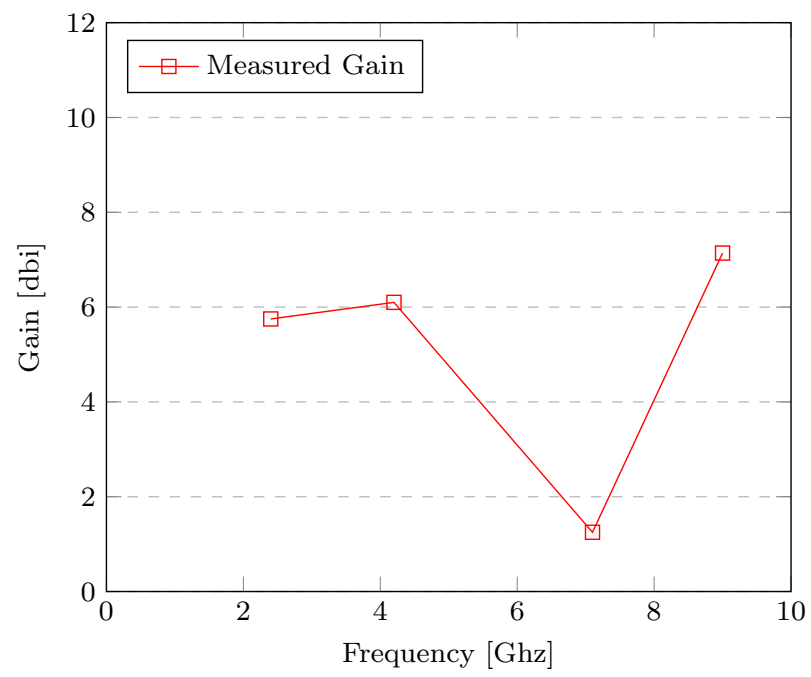

Fig. 9: Gain of slotted PIFA

Table 3: Comparison of proposed slotted PIFA with the previous literature

\begin{tabular}{ccccc}
\hline Ref. & Size & $\begin{array}{l}\text { No } \\
\text { of } \\
\text { band }\end{array}$ & $\begin{array}{c}\text { Oprating } \\
\text { Freq(GHz) }\end{array}$ & $\begin{array}{c}\text { Gain } \\
(\mathrm{dBi}))\end{array}$ \\
\multicolumn{7}{c}{} & & & \\
\hline$[5]$ & $25.6 \times 26 \times 3.57$ & 3 & $2.09 / 3.74 / 5$ & $2.05 / 2.32 / 3.47$ \\
{$[8]$} & $34 \times 17 \times 8$ & 3 & $0.9 / 1.7 / 2.4$ & $0.4 / 1.7 / 1.1$ \\
{$[10]$} & $16.5 \times 11.5 \times 5$ & 3 & $2.4 / 5.2 / 5.8$ & $4.44 / 4.91 / 4.94$ \\
{$[14]$} & $90 \times 42 \times 7.5$ & 4 & $1.1 / 2.4 / 3.6 / 5.3$ & $1.45 / 1.6 / 3.56 / 4$ \\
{$[16]$} & $25 \times 11 \times 8$ & 3 & $2.4 / 5.2 / 5.75$ & $1.6 / 2.3 / 4.4$ \\
{$[17]$} & $26 \times 20 \times 1.6$ & 3 & $2.4 / 3.5 / 5.8$ & $2.24 / 2.8 / 2.6$ \\
{$[18]$} & $100 \times 65 \times 1.6$ & 3 & $0.9 / 1.8 / 2.6$ & $0.25 / 0.6 / 3.28$ \\
Prop & $23.33 \times 2.66 \times 2.59$ & 4 & $2.4 / 4.2 / 7.1 / 9$ & $5.75 / 6.10 / 1.25 / 7.14$ \\
Work & & & &
\end{tabular}

simulated results and calculated results of the return loss $\left(S_{11}\right)$, and VSWR increased marginally due to the wide air distance between the radiating patch and the ground plane prepared during the manufacturing process. For a mobile application, the designed antenna is helpful to demonstrate the strong matching impedance. The photograph of the manufactured slotted PIFA with RIS has shown in Fig. 10. Table 3 illustrates the details of the comparison between proposed slotted PIFA in terms of all geometric dimensions, miniaturization, frequency range, gain, and bandwidth with previous work. 


\subsection{VSWR}

Fig. 8(b) shows the measured VSWR of the slotted PIFA with RIS. It noted that the VSWR value is almost 1.60 at the $2.4 \mathrm{GHz}$ frequency that is effective in the manufacturing phase. The slotted PIFA VSWR is 1.60,2.07, 2.55, and $2.79 \mathrm{~dB}$ observed for operating bands $2.4,4.2,7.1$, and $9 \mathrm{GHz}$, respectively. The lower the VSWR, it more suits the power transmitted to the antenna the transmission line it means that better matching of impedance and the antenna's input power to the patch.

\subsection{Gain}

The gain of the slotted PIFA for a handheld device, as shown in Fig. 9, is acceptable for the better multiband antenna. The slotted PIFA gain is 5.75, $6.10,1.25$, and $7.14 \mathrm{dBi}$ observed for operating bands 2.4, 4.2, 7.1, and $9 \mathrm{GHz}$, respectively. The averagely gain of an antenna for a quad-band is $5.06 \mathrm{dBi}$ across their operating bandwidth.

\subsection{Radiation pattern}

The radiation pattern of slotted PIFA simulated in HFSS for the E-plane and $\mathrm{H}$-plane. The radiation pattern depends on the magnetic field and electric field of the slotted PIFA. For multiband, the slotted PIFA radiates when the wave path alongside the Z-axis (-Z path and $+\mathrm{Z}$ path) then an antenna's port 1 , is excited in the simulation. In this Fig. 11, the slotted PIFA radiation path deviates from the $\mathrm{Z}$-axis towards the $\mathrm{X}-\mathrm{Z}$ right plane to the $\mathrm{Y}-\mathrm{Z}$ left the plane. The radiation pattern of the antenna (co-plane and cross-plane) illustrate in Fig.11 (a), (b), (c), (d), (e), (f), (g), and (h) of the X-Z plane, and Y-Z plane for the $\phi=0^{\circ}$ and $\phi=90^{\circ}$ at $2.4,4.2,7.1$ and $9 \mathrm{GHz}$ in measurement respectively.

\section{CONCLUSION}

A compact, multiband slotted PIFA with RIS presented for WiMax, C-band satellite downlink, C-band satellite uplink, and X-band applications. The slotted PIFA exhibit multiband with $S_{11}<-10 \mathrm{~dB}$ bandwidth of about $15.83 \%$, $11.19 \%, 12.67 \%$ and $10.55 \%$ at $2.4,4.2,7.1$ and $9 \mathrm{GHz}$ in measurement respectively. Parametric analysis reveals that the small change in the rectangular slots significantly impacts the antenna impedance matching. It also increases the bandwidth and provides better gain with the same dielectric substrate and radiating patch. The advantage multiple bands illustrate on the slotted PIFA exhibits radiation pattern, wideband, impedance matching, and gain across their operating bandwidths. 


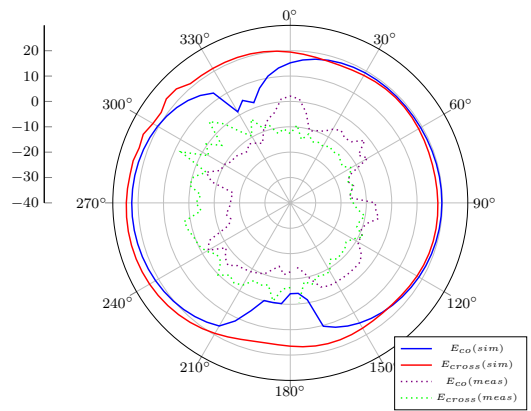

(a) $\mathrm{X}-\mathrm{Z}$ plane, $2.4 \mathrm{GHz}$

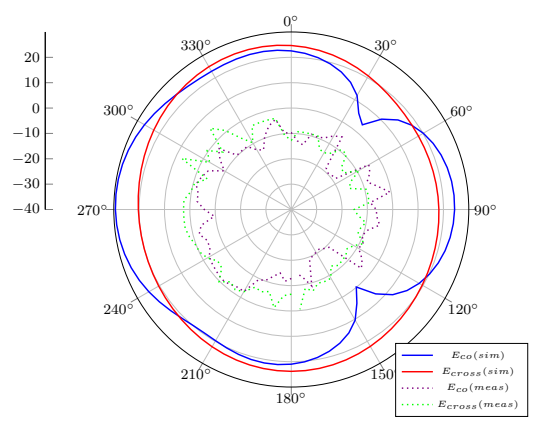

(c) X-Z plane, $4.2 \mathrm{GHz}$

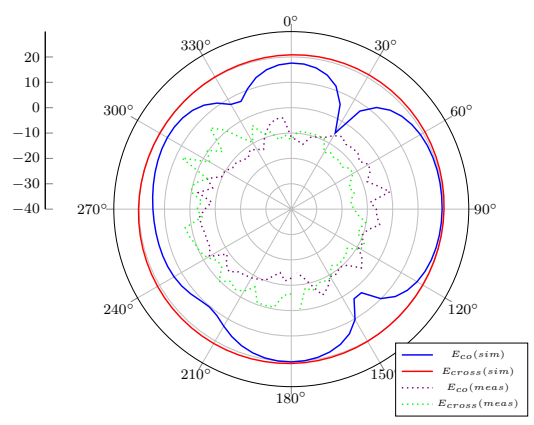

(e) X-Z plane, $7.1 \mathrm{GHz}$

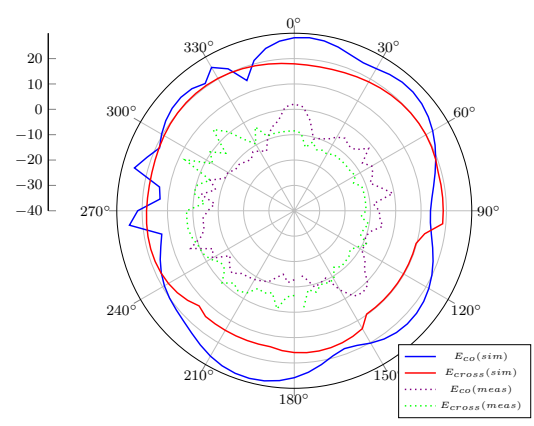

(g) X-Z plane, 9 GHZ

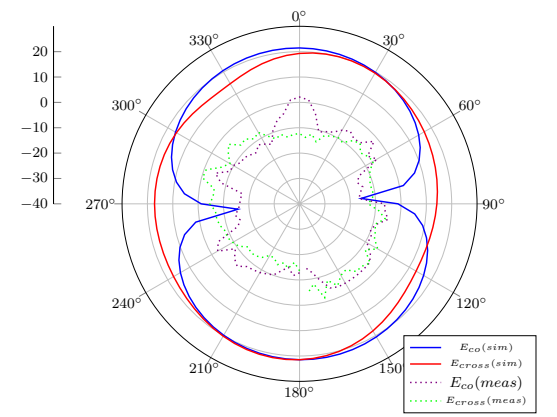

(b) Y-Z plane, $2.4 \mathrm{GHz}$

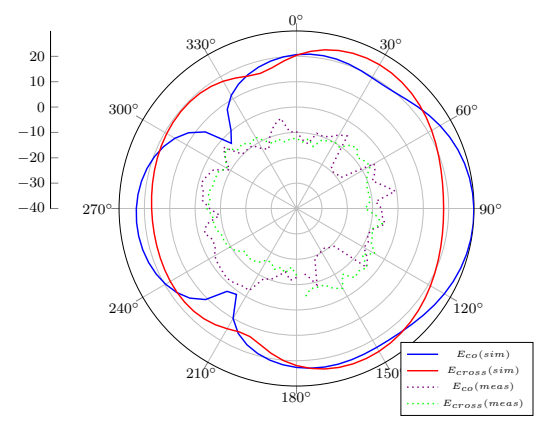

(d) Y-Z plane, $4.2 \mathrm{GHz}$

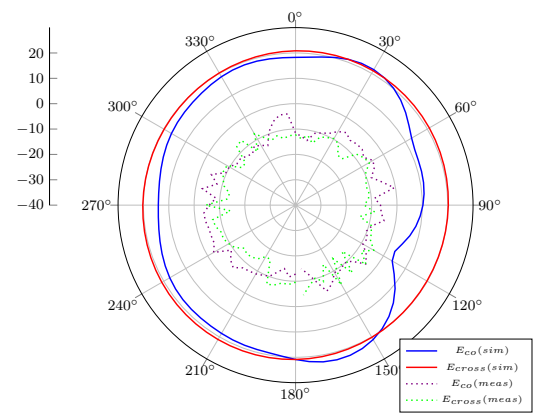

(f) Y-Z plane, $7.1 \mathrm{GHz}$

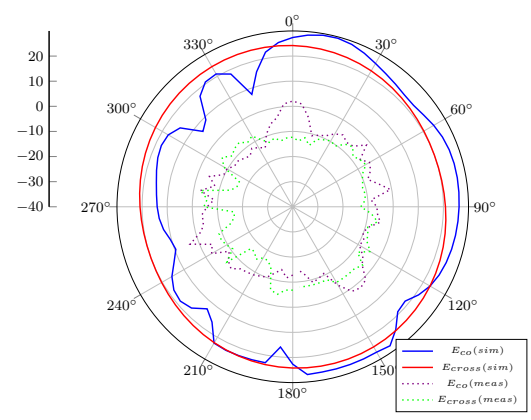

(h) Y-Z plane, $9 \mathrm{GHz}$

Fig. 10: Radiation pattern X-Z and Y-Z planes of slotted PIFA at 2.4, 4.2, 7.1 and $9 \mathrm{GHz}$ 


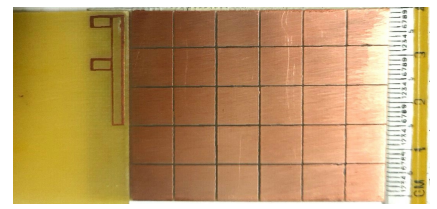

(a) slotted PIFA with RIS

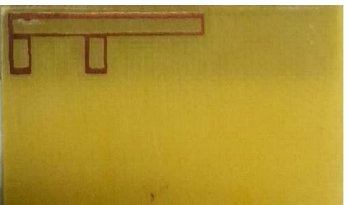

(b) Top view of slotted PIFA

Fig. 11: photograph of slotted PIFA with RIS

\section{References}

1. Lev Pazin and Yehuda Leviatan. Narrow-size multiband inverted-f antenna. IEEE Antennas and Wireless Propagation Letters, 10:139-142, 2011.

2. Kin-Lu Wong and Kai-Ping Yang. "Modified planar inverted $\mathrm{f}$ antenna", Electronics letters, 34(1):7-8, 1998.

3. Dalia M Elsheakh and Esmat A Abdallah. "Compact multiband multifolded-slot antenna loaded with printed-ifa", IEEE antennas and wireless propagation letters, 11:1478-1481, 2012.

4. IJ Garcia Zuazola and John C Batchelor. "Compact multiband pifa type antenna", Electronics letters, 45(15):768-769, 2009.

5. Hattan F AbuTarboush, R Nilavalan, Thomas Peter, and SW Cheung. "Multiband inverted-f antenna with independent bands for small and slim cellular mobile handsets", IEEE Transactions on Antennas and Propagation,59(7):2636-2645, 2011.

6. RGM Oliveira, AJM Sales, JPC Nascimento, JWM Menezes, MAS Silva, and ASB Sombra. "Compact triple-band pifa with high bandwidth and gain for multiple mobile services", Microwave and Optical Technology Letters, 58(12):2961-2965,2016.

7. Yamina Belhadef and Nourediene Boukli Hacene. "Design of new multiband slotted pifa antennas", International Journal of Computer Science Issues (IJCSI), 8(4):325, 2011.

8. Dongsheng Qi, Binhong Li, and Haitao Liu. "Compact triple-band planar inverted-f antenna for mobile handsets", Microwave and optical technology letters, 41(6):483-486, 2004.

9. Saidatul Norlyana Azemi, Azremi Abdullah Al-Hadi, Raad Badlishah Ahmad, Ping Jack Soh, and Fareq Malek. "Multiband fractal planar inverted f antenna (f-pifa) for mobile phone application", Progress In Electromagnetics Research, 14:127-148, 2009.

10. Hanyang Wang and Ming Zheng. "An internal triple-band wlan antenna", IEEE Antennas and Wireless Propagation Letters, 10:569-572, 2011.

11. Mustapha El Halaoui, Abdelmoumen Kaabal, Hassan Asselman, Saida Ahyoud, and Adel Asselman. "Multiband planar inverted-f antenna with independent operating bands control for mobile handset applications", International Journal of Antennas and Propagation, 2017, 2017.

12. Jae-Hyeong Ko, Koon-Tae Kim, Dong-Hun Kim, Hyang-Beom Lee, and Hyeong-Seok Kim. "A practical approach to robust design of a rfid triple-band pifa structure", IEEE transactions on magnetics, 46(8):3333-3336, 2010.

13. Benito Sanz-Izquierdo, John Batchelor, and Richard Langley. "Multiband printed pifa antenna with ground plane capacitive resonator", Electronics letters, 40(22):1391-1392, 2004.

14. Bahareh Mansouri, Zaker Hossein Firouzeh, Reza Safian, Farzaneh Arab Juneghani, and Afsoun Soltani. "A multi-band microstrip planar inverted-f antenna for wireless applications", Journal of Communication Engineering, 2020.

15. Anupa Chatterjee, Manas Midya, Laxmi Prasad Mishra, and Monojit Mitra. "Compact dual polarised branch-line printed inverted-f antenna covering both cellular and noncellular bands with independent tuning", Progress In Electromagnetics Research, 101:95$104,2020$. 
16. Shaoli Zuo, Yingzeng Yin, Zhiya Zhang, and Weijun Wu. "A compact tri-band pifa antenna for wlan and wimax applications", Microwave and Optical Technology Letters, 52(4):919-922, 2010.

17. Li Li, Xiaoliang Zhang, Xiaoli Yin, and Le Zhou. A compact triple-band printed monopole antenna for wlan/wimax applications. IEEE antennas and wireless propagation letters, 15:1853-1855, 2016 .

18. Arpan Desai, Trushit Upadhyaya, Jay Patel, Riki Patel, and Merih Palandoken. Flexible cpw fed transparent antenna for wlan and sub-6 ghz $5 \mathrm{~g}$ applications. Microwave and Optical Technology Letters, 62(5):2090-2103, 2020.

19. Jwo-Shiun Sun, Han-Sheng Fang, Po-Yen Lin, and Ching-Song Chuan "Triple-band mimo antenna for mobile wireless applications",IEEE Antennas and Wireless propagation letters, 15:500-503, 2015.

20. Arpan Desai, Trushit Upadhyaya, Merih Palandoken, and Cem Gocen. Dual band transparent antenna for wireless mimo system applications. Microwave and Optical Technology Letters, 61(7):1845-1856, 2019.

21. Riki Patel, Trushit Upadhyaya, Arpan Desai, and Merih Palandoken. Low profile multiband meander antenna for lte/wimax/wlan and insat-c application. AEU-International Journal of Electronics and Communications, 102:90-98, 2019.

22. Nicole L Bohannon and Jennifer T Bernhard. "Design guidelines using characteristic mode theory for improving the bandwidth of pifas", IEEE Transactions on Antennas and Propagation, 63(2):459-465, 2014.

23. Mei Yang, Zhi Ning Chen, Pui Yi Lau, Xianming Qing, and Xiaoxing Yin. "Miniaturized patch antenna with grounded strips",

24. Tejaswi Jadhav and Shraddha Deshpande. "Miniaturized planar inverted-f antenna with metallic cross branch for mobile communication", In 2019 International Conference on Intelligent Computing and Control Systems (ICCS), pages 617-620. IEEE, 2019.

25. Tejaswi Jadhav and Shraddha Deshpande. "Planar inverted-f antenna using defected ground surface for mobile application",In ICDSMLA 2019, pages 611-619. Springer, 2020.

26. Tejaswi Jadhav and Shraddha Deshpande. "Wideband circularly polarized planer inverted-f antenna using reactive impedance surface",International Journal of Innovative Technology and Exploring Engineering,2019

27. Constantine A Balanis. "Antenna theory: analysis and design",John wiley \& sons, 2016. 